\title{
ON THE MECHANISM OF OVERPRODUCTION OF URIC ACID IN PATIENTS WITH PRIMARY GOUT ${ }^{1}$
}

\author{
By JAMES B. WYNGAARDEN, ALBERTA E. BLAIR, AND LINNELLE HILLEY \\ (From the Department of Medicine, Duke University School of Medicine, Durham, N. C., and \\ the National Institute of Arthritis and Metabolic Diseases, National Institutes \\ of Health, Bethesda, Md.)
}

(Submitted for publication October 2, 1957; accepted December 26, 1957)

In order to study the rate of generation of uric acid in man, Benedict, Roche, Yü, Bien, Gutman, and Stetten (5-7) administered relatively large doses of glycine- $\mathrm{N}^{15}$ orally to control and gouty subjects and measured the appearance of isotope in urinary uric acid. With this technique, they demonstrated overincorporation of isotope into uric acid only in gouty subjects excreting large quantities of uric acid in urine. Subsequently, however, excessive incorporation of tracer quantities of glycine-1-C ${ }^{14}$ into uric acid was demonstrated in all of seven subjects studied, regardless of the stage of severity of the disease or of the magnitude of urinary uric acid excretion (8). These results indicated that overproduction of uric acid from glycine and other small molecules was the fundamental defect responsible for hyperuricemia in primary gout. The characteristics of the curves of uric acid enrichment indicated that excessive biosynthesis of uric acid occurred in these gouty subjects without the intermediary intervention of nucleic acids $(5,7,8)$.

Since the mechanism of overproduction of uric acid in primary gout has not been defined in detail, it was decided to investigate the incorporation of glycine-1- $\mathrm{C}^{14}$ into various urinary purine bases and to compare enrichment patterns with those of uric acid determined simultaneously. From such comparisons, information was sought regarding purine intermediates involved in normal and abnormal uric acid production. These studies have suggested two types of mechanism resulting in uric acid synthesis in man and have strengthened the present concepts $(5,7,8-12)$ that over-

1 This work has been supported, in part, by grants from the National Institutes of Health, United States Public Health Service, Grant No. A-1391, and from the United Medical Research Foundation of North Carolina. Preliminary reports of this work have appeared in abstract form (1-3), and certain aspects have been included in a recent review article (4). production of uric acid may occur by one mechanism in primary gout and by another in proliferative hematopoietic disorders of the type associated with secondary gout.

\section{METHODS}

Materials and instruments. Glycine-1-C $\mathrm{C}^{\mathbf{4}}, 1$ to $2 \mathrm{mc}$. per $\mathrm{mM}$, was purchased from Nuclear Instrument and Chemical Corporation, Chicago. Purified uricase, xanthine oxidase, and catalase were purchased from Worthington Biochemicals Corp. Guanase was prepared from rat liver according to Kalckar (13). Adsorption readings and enzymatic analyses were made in a Beckman DU ultraviolet spectrophotometer. Spectra were determined in a Beckman DK ultraviolet recording spectrophotometer. Chromatographic elution fractions were analyzed for compounds absorbing at $253 \mathrm{~m} \mu$ in a Gilson ultraviolet scanner and traced by an EsterlineAngus recorder; fractions were collected in a Gilson volumetric fraction collector. $\mathrm{C}^{14}$ measurements were made in a Robinson gas-flow counter.

Subjects. Pertinent data on subjects of this study are given in Table I. All subjects ingested a purine poor diet for a preparatory period of about five days and for the duration of the study. This diet contained about $30 \mathrm{mg}$. of purine-N and 55 to $60 \mathrm{Gm}$. of protein. Glycine-1-C ${ }^{14}$ was administered in solution orally with breakfast to four control subjects, three subjects with primary gout, one subject with polycythemia vera and secondary gout, and one subject with myeloid metaplasia. Subjects received from 2.5 to $25 \mu \mathrm{c}$. of $\mathrm{C}^{14}$.

Collections and analyses. Twenty-four hour urine collections were obtained under toluene at room temperature from the second day of dietary preparation and continuously thereafter for periods up to 24 days. When the urinary uric acid excretion had reached a stable low value, glycine-1-C $\mathrm{C}^{\mathbf{1 4}}$ was administered. Thereafter, samples were collected and stored at $-10^{\circ} \mathrm{C}$. until analyzed. Uric acid analyses on urine and serum were performed by differential spectrophotometry $(14,15)$ employing purified uricase.

Urinary purines were precipitated with copper and dissolved in $\mathrm{HCl}$ according to the Hunter and Givens modification (16) of the procedure of Krüger and Schmid (17). On reduction of volume and chilling of the acid solution, uric acid precipitated and was col- 


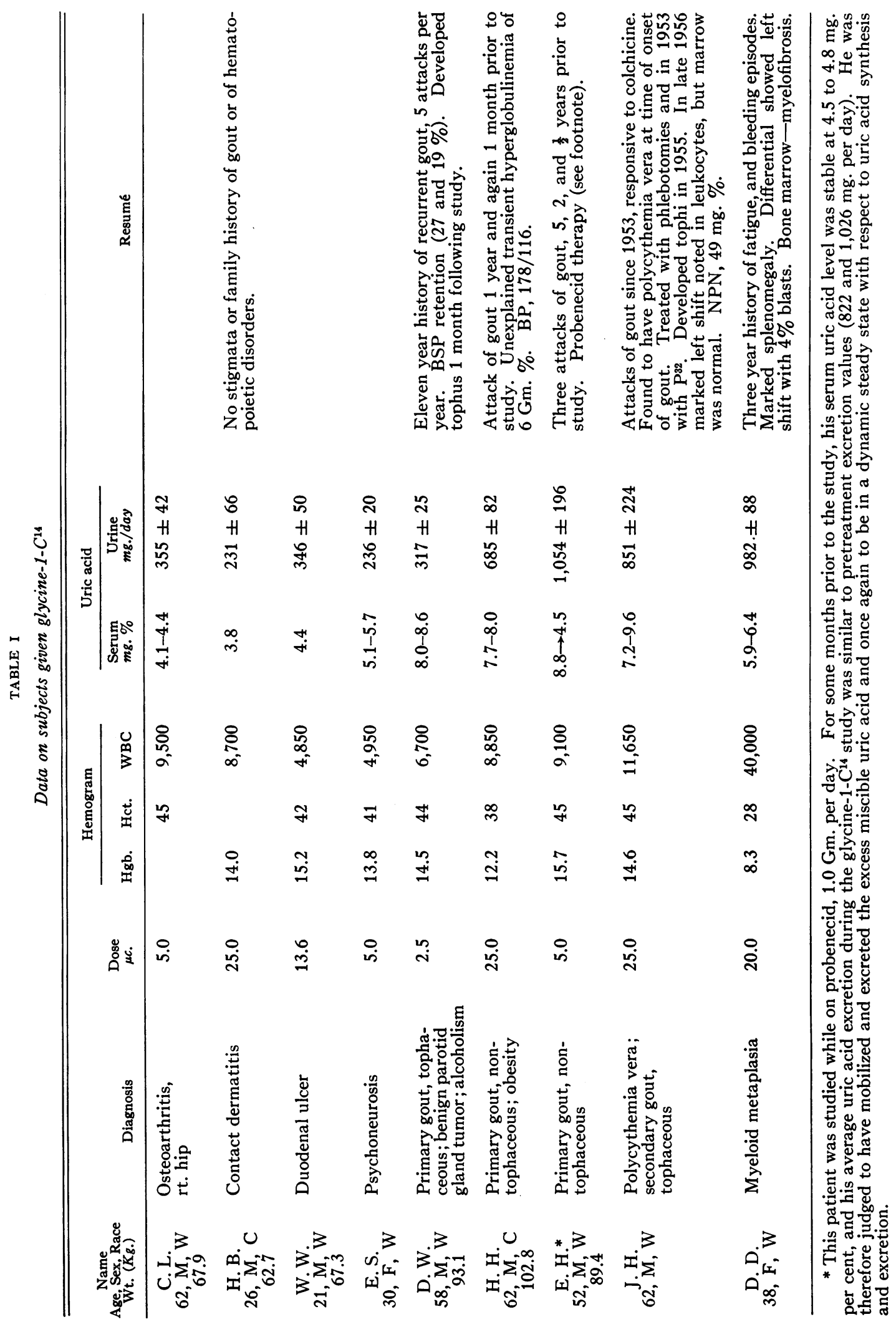


lected for subsequent recrystallization $(8,18)$ and $\mathrm{C}^{14}$ analysis. The filtrate, containing the urinary purine bases as soluble hydrochlorides, was then treated with ammoniacal silver nitrate and stored in the cold (19). The washed silver salts were decomposed with a minimal quantity of $\mathrm{HCl}$, and the purine hydrochlorides separated from the $\mathrm{AgCl}$ precipitate by centrifugation. This silver precipitation step effected a further purification of the purine bases, which were eventually recovered in a solution of $\mathrm{HCl}$ of known strength. This solution was diluted to $0.15 \mathrm{~N}$ with respect to $\mathrm{HCl}$ and was then added to a Dowex-50- $\mathrm{H}^{+}$column, $12 \mathrm{X}, 200$ to 400 mesh. In the last two studies (control H. B. and gouty subject H. H.) urinary purines were isolated by preliminary segregation on Dowex $-50-\mathrm{H}^{+}$according to Weissmann, Bromberg, and Gutman (20) and eventually also placed on the analytical column in dilute $\mathrm{HCl}$. The analytical column, $2.5 \mathrm{~cm}$. in diameter, contained $150 \mathrm{ml}$. of resin in acid form, ${ }^{2}$ washed with water till free of $\mathrm{Cl}^{-}$. The sample was washed into the column with $50 \mathrm{ml}$. of water, and then elution of purines was started with $0.15 \mathrm{~N} \mathrm{HCl}$, under 2 to 4 p.s.i. added air pressure. A continuous frontal analysis of the elution of ultraviolet absorbing compounds was obtained with the recording UV scanner. After passage through the quartz cell of the absorption meter, the eluate was collected in $24 \mathrm{ml}$. fractions.

Uric acid was not retained by the resin, and the small quantities remaining in the sample after the copper isolation procedure were quickly washed through the column. At about tube No. 65 xanthine appeared. As soon as xanthine was removed, the elution system was changed so as to provide an acid gradient for the remainder of the process. This technique is a modification of the stepwise elution procedure described by Abrams and Bentley (21) and Wall (22). ${ }^{3}$ A double reservoir was put in place in which the upper flask, a three-liter separatory funnel, containing $2.2 \mathrm{~L}$. of $2.67 \mathrm{~N} \mathrm{HCl}$, was arranged to feed into the lower flask, a two-liter bottle with an outlet near its base, containing $2.0 \mathrm{~L}$. of $0.15 \mathrm{~N} \mathrm{HCl}$, as the contents of the latter flowed on the column. Mixing was effected within the lower chamber by means of a magnetic stirrer, and the rate of elution was maintained at about $3 \mathrm{ml}$. per minute by means of 1 to 2 p.s.i. added air pressure. The identity of the compounds comprising the various peaks was established by comparison with known compounds as to elution sequence, spectral characteristics at $\mathrm{pH} 2,6$ and 9,250/260 and 280/260 $\mathrm{m} \mu$ absorption ratios, response to xanthine oxidase (xanthine, hypoxanthine, adenine) or to guanase in the presence of

2 Dowex $-50-\mathrm{H}^{+}$resin was prepared by preliminary washing twice each with $2 \mathrm{~N} \mathrm{NaOH}$ and $4 \mathrm{~N} \mathrm{HCl}$, the last $\mathrm{HCl}$ wash being performed in the column and continued until ultraviolet absorbing impurities were removed.

3 Weissmann, Bromberg, and Gutman (20) have also recently developed a modification of the Wall procedure for use in separation of urinary purines. Their method is similar to that described herein, except that stronger concentrations of $\mathrm{HCl}$ were employed. xanthine oxidase (guanine, 1-methylguanine), and migration on two-dimensional paper chromatograms (23).4

The fractions representing a single peak were pooled, and analyzed quantitatively. Xanthine and hypoxanthine were analyzed with xanthine oxidase according to Kalckar (14). Adenine was analyzed with xanthine oxidase in the presence of catalase according to Klenow (24). Compound S, separated from adenine on paper in butanol-ammonia $(20,23)$ and eluted by downward irrigation with $0.01 \mathrm{~N} \mathrm{HCl}$, was shown not to be a substrate for xanthine oxidase, so that adenine analyses could be conducted enzymatically on the buffered mixed sample obtained from the column. Guanine was assayed with guanase in the presence of xanthine oxidase according to Kalckar (13). The methylguanine fraction was assayed by ultraviolet absorption alone, since 7-methylguanine, the major constituent, is not responsive to guanase (25) or xanthine oxidase (26). 1-Methylguanine, the other component, is deaminated by guanase (25), and the product, 1-methylxanthine, is a substrate for xanthine oxidase (27). These reactions permitted the estimate that about 10 per cent of the total methylguanine fraction was the 1-methyl isomer. However, since these compounds rarely separated-satisfactorily on Dowex-50 or on paper $(20,23)$, the mixture was treated as a single fraction, and expressed as 7-methylguanine.

The major goal of the present methods was isolation of the purine bases in quantities sufficient for isotope analysis. Therefore, the appropriate fractions were routinely pooled and reduced to dryness in vacuo at $30^{\circ} \mathrm{C}$. in a rotary evaporator. Thereafter, the residue was redissolved (or suspended) in a few $\mathrm{ml}$. of water and transferred to a $12 \mathrm{ml}$. conical test tube. Xanthine was purified by solution in $0.5 \mathrm{~N} \mathrm{NaOH}$, decolorized with Norit, and reprecipitated with acetic acid. 7-Methyl-8-hydroxyguanine was recrystallized from $\mathrm{HCl}$ by addition of water according to Weissmann, Bromberg, and Gutman (28). Hypoxanthine was isolated as the silver picrate and recrystallized from concentrated $\mathrm{HNO}_{3}$ (29). 7-Methylguanine was precipitated from dilute $\mathrm{HCl}$ with ammonium hydroxide at $\mathrm{pH} 9$ and chilling. It was purified by solution in $2 \mathrm{~N} \mathrm{HCl}$, decolorized with Norit, and reprecipitated by adjustment of the filtrate to $\mathrm{pH} 9$ with ammonium hydroxide. ${ }^{5}$ Adenine was isolated as the picrate

4 Xanthine, hypoxanthine, guanine, and adenine standards were available. Their spectra, and 250/260 and 280/260 $\mathrm{m} \mu$ absorption ratios were obtained in $\mathrm{HCl}$ eluates from the column, which thereafter served as references for characterizations of peaks from urine samples. 7-Methylguanine was identified by comparison with spectral data published by Weissmann, Bromberg, and Gutman (20). 7-Methylxanthine, 7-methyl-8-hydroxyguanine, 1-methylhypoxanthine, $\mathrm{N}^{2}$-methylguanine, 1-methylguanine and " $\mathrm{S}$ " were identified by their positions on two-dimensional paper chromatograms, and spectral data following elution from these papers, in comparison with published data $(20,23)$.

5 The purity of the foregoing compounds was checked frequently during the course of these investigations. 
TABLE II

Purity of adenine picrate

\begin{tabular}{cc}
\hline Sample & $c p m / m M$ \\
\hline Picrate of "adenine-S mixture" & 782 \\
Picrate of pure adenine & 706 \\
\hline
\end{tabular}

and recrystallized from 25 per cent acetic acid (30). The purity of the adenine picrate was demonstrated as follows: An adenine picrate sample was redissolved in $0.01 \mathrm{~N} \mathrm{HCl}$, and the picrate removed by repeated extractions with ether (31). The aqueous solution was then placed on filter paper as a band, and a descending chromatogram developed with butanol-ammonia. Following drying of the paper, a single band was seen in ultraviolet light opposite an adenine marker, whereas no absorbing material was seen opposite a compound $\mathrm{S}$ marker. The adenine was eluted, and its picrate again prepared. The specific activities of the original and final preparations of adenine picrate were in good agreement (Table II). The preparation of the picrate, therefore, was an effective means of separating adenine from compound $\mathrm{S}$ for isotope analysis.

Guanine was not present in urine in sufficient quantity to permit isolation as a crystalline product. Therefore, after the quantity of guanine in the column eluate was established by enzymatic analysis (average ca., 0.3 $\mathrm{mg}$ ), 2 to $3 \mathrm{mg}$. of carrier guanine were added, and the solution was reduced to dryness, redissolved in a few $\mathrm{ml}$. of water and guanine isolated by neutralization of the solution with $\mathrm{NaOH}$ and chilling (30). In other cases also, where the quantities of purine separated from the column were very small, as in 6 to 12 hour urine samples, small quantities of the appropriate carrier were added.

The crystalline products were sparingly washed with iced water, dried in vacuo at $100^{\circ} \mathrm{C}$., and transferred to stainless steel planchets as suspensions in acetone or absolute alcohol, dried under an infra-red lamp, and counted in a Robinson gas-flow counter (32) having a background of $4 \mathrm{cpm}$, and an efficiency of 53 per cent at infinite thinness. Counting was conducted to less than 10 and usually to less than 5 per cent error (33), and all counting values were corrected to a standard mass of $3.3 \mathrm{mg}$. per $1.54 \mathrm{~cm}^{2}$ surface area by means of self-absorption correction curves. At this mass, the counting efficiency is 26 per cent. Appropriate conversion factors were em-

The values for hypoxanthine and xanthine obtained from the optical density readings of the column eluates agreed with values obtained from analyses with xanthine oxidase (14). Also, the concentrated eluates were shown to yield but one ultraviolet absorbing spot each when checked by two-dimensional chromatography (23). Furthermore, when the crystalline free bases xanthine, 7-methylguanine, and 7-methyl-8-hydroxyguanine were recovered from planchets, redissolved in $\mathrm{HCl}$, and rechromatographed on paper, they appeared pure. ployed to permit direct comparison of counting values of purine derivatives with free bases.

\section{RESULTS}

\section{Separation of urinary purines}

A typical elution pattern is illustrated in Figure 1. Uric acid was washed off the resin with water. Immediately following the uric acid peak, there appeared a small second peak (a) of unknown identity. At about tube No. 65, xanthine appeared, and thereafter, following the changeover to the gradient elution procedure, the other purine bases appeared sequentially as indicated in Figure 1. The tube number at which a specific purine base appeared seldom varied by more than two or three from that indicated in the figure, in about 120 separate sample isolations. At about tube No. 110 , a second unknown appeared (b). Substances $a$ and $b$ exhibit only sweeping end-absorption in the ultraviolet, and do not migrate in the twodimensional paper chromatogram. Compound $\mathrm{S}$ appears to be identical with the compound so labeled by Weissmann, Bromberg, and Gutman (20). Substance $c$ was inconstant. It did not migrate on the two-dimensional chromatogram. When purines are isolated by initial segregation on Dowex-50, the elution pattern from the analytical column does not contain uric acid, peak a or peak c, and small peaks or shoulders representing compounds V and W (20) are found. None of the

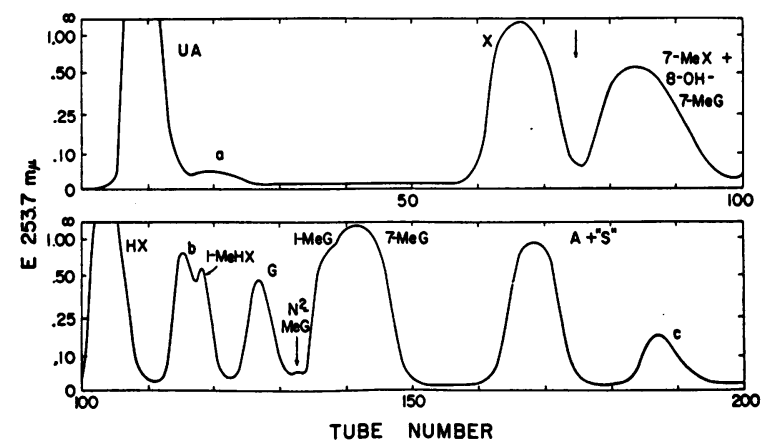

Fig. 1. Chromatographic Separation of Urinary Purines

Urinary purines, isolated by sequential copper and silver precipitations, were separated on Dowex $-50-\mathrm{H}^{+}$ resin by elution with $\mathrm{HCl}$. Initial elution was with 0.15 $\mathrm{N} \mathrm{HCl}$. After appearance of xanthine, gradient elution was begun with $2,200 \mathrm{ml}$. of $2.67 \mathrm{~N} \mathrm{HCl}$ in the upper reservoir and $2,000 \mathrm{ml}$. of $0.15 \mathrm{~N} \mathrm{HCl}$ in the lower reservoir. Fractions equal $24 \mathrm{ml}$. each. 


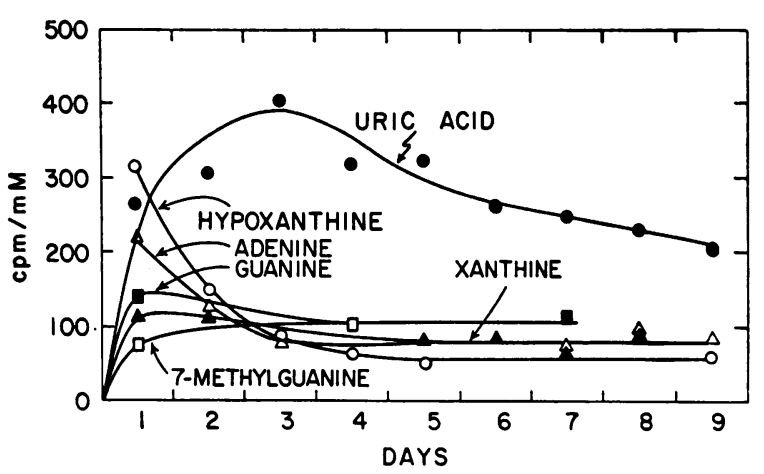

Fig. 2. Specific Activity Values of Urinary Purines of Control Subject C. L., Following Oral Administration of $5 \mu \mathrm{c}$. of Glycine-1-C ${ }^{14}$

ultraviolet absorbing compounds gives an orcinol test (34) for pentose, so there is no suspicion that any of the compounds are ribosides. Indeed, ribosides, if present, would in all likelihood have been hydrolyzed during the initial isolation procedure.

\section{Labeling of urinary purines in control subjects}

Figure 2 shows the labeling pattern of hypoxanthine, adenine, xanthine and uric acid, and of a few samples of guanine and 7-methylguanine, in control subject C. L. following administration of $5 \mu \mathrm{c}$. of glycine-1- $\mathrm{C}^{14}$. Hypoxanthine and adenine were maximally enriched on Day 1 , and thereafter rapidly declined to rather low levels of isotope concentration. Xanthine enrichment was also somewhat greater on Days 1 and 2 than on subsequent days, but there was no clear-cut peak on Day 1 as with hypoxanthine and adenine. The scattered samples of guanine and 7-methylguanine ${ }^{6}$ similarly do not suggest that either was as highly labeled at any time as were hypoxanthine or adenine. Uric acid attained maximal isotope concentration on Day 3, whereafter a slow decline ensued. Hypoxanthine was the only urinary purine base showing $\mathrm{C}^{14}$ concentration greater than that of uric acid on Day 1.

\footnotetext{
${ }^{6}$ It appears likely that 7-methylguanine is derived from guanine rather than from more complex guanine compounds, since only in the free base form is there a replaceable hydrogen on N-7. Thus, the labeling patterns of 7-methylguanine are believed to reflect those of guanine, and therefore also those of guanylic acid. Data shown in Figure 10, and to some extent Figure 2, support the interpretataions of the significance of 7-methylguanine labeling values, although the interpretations are only inferential.
}

In order to elucidate more clearly the events occurring immediately following administration of glycine, a second control subject, $\mathrm{H}$. B., was given $25 \mu \mathrm{c}$. of glycine-1- $\mathrm{C}^{14}$ and fractional urine samples were obtained initially. Uric acid became maximally labeled in the 6 to 17 hour sample (Figure 3 ), the earliest time a maximum has been observed in a normal subject. However, cumulative incorporation of $\mathrm{C}^{14}$ into urinary urate in 2.75 days was 0.064 per cent of the administered dose, an entirely normal value (8). Hypoxanthine enrichment was maximal in the 0 to 6 hour sample and its specific activity was three times that of uric acid of the same specimen, and almost two times the maximal uric acid value, attained during the next 11 hour period. Hypoxanthine enrichment promptly fell to rather low specific activity values. Adenine was also maximally labeled in the 0 to 6 hour specimen and declined in isotope concentration thereafter. In contrast, xanthine and 7-methylguanine showed rather low specific activity values in the 0 to 6 hour specimen, and passed through isotope concentration maxima in the 6 to 17 hour period, declining strikingly immediately thereafter. The parallelisms of the hypoxanthine and adenine curves and of the xanthine and 7-methylguanine curves are to be noted.

These studies strongly suggest that the rapid

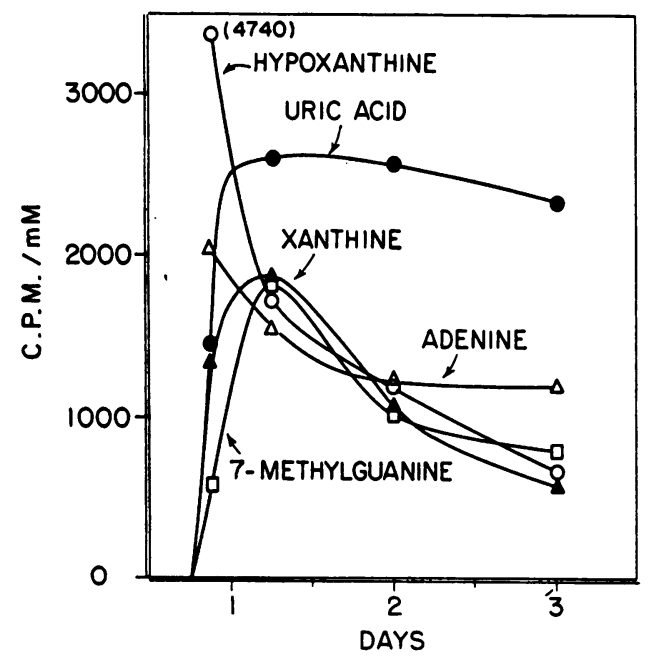

Fig. 3. Specific Activity Values of Urinary Purines of Control Subject H. B., Following Oral Administration of $25 \mu \mathrm{c}$. of Glycine-1-C ${ }^{14}$

One 6 , one 12 , and two 24 hour urine specimens were collected. Note particularly the very high initial $\mathbf{C}^{\mathbf{1 4}}$ content of hypoxanthine. 


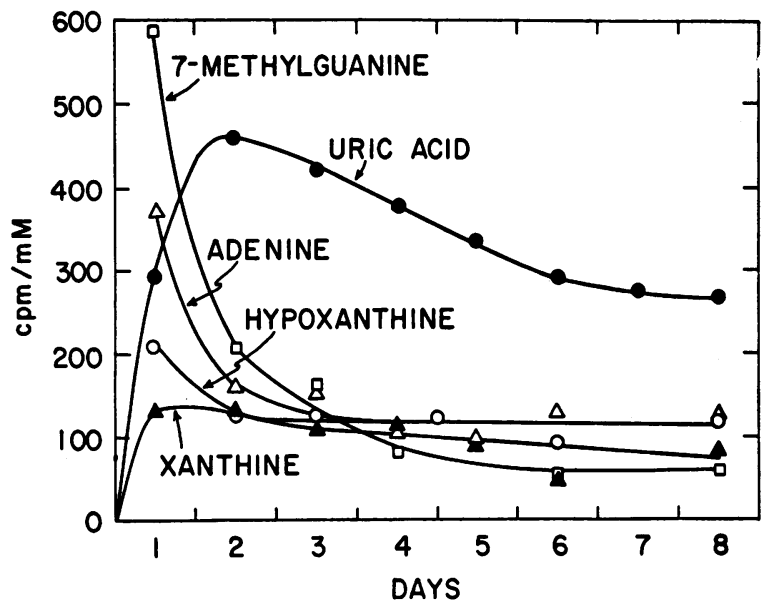

Fig. 4. Specific Activity Values of Urinary Purines of Gouty Subject D. W., Following Oral AdMinistration of $2.5 \mu$ c. of GLycine-1-C ${ }^{14}$

Note the high initial enrichment value of 7-methylguanine.

Permission was granted by Grune \& Stratton, Inc. to reproduce this figure which originally appeared in METABOLISM, volume 6, pp. 244-268, 1957.

synthesis of labeled uric acid from glycine-1- $\mathrm{C}^{\mathbf{1 4}}$ in control subjects proceeds via hypoxanthine compounds and probably free hypoxanthine as a major intermediate. The most direct pathway employing known reactions involves stepwise build up of glycine to inosinic acid $(29,35-39)$, dephosphorylation to yield inosine (39), phosphorolytic cleavage to yield hypoxanthine (40, 41 ), and oxidation of hypoxanthine to uric acid $(14,27)$. One would anticipate that enrichment values of xanthine would reflect its role as product of hypoxanthine and precursor of uric acid in this sequence. A possible explanation of the pattern observed is that hypoxanthine once bound by xanthine oxidase is not appreciably displaced from the enzyme until fully oxidized to uric acid, and that urinary xanthine is derived from organs not actively participating in rapid urate synthesis, or perhaps primarily from guanine rather than from hypoxanthine. The early maxima of adenine, 7-methylguanine and xanthine suggest that all of the newly formed nucleotides may be subject in part to cleavage reactions, and that several pathways may contribute to early labeling of uric acid. However, the initial specific activity data suggest that inosinic acid cleavage may normally be quantitatively the most important of these pathways. Thus, the direct synthesis of uric acid in normal man may well involve primarily the same pathway employed by the bird in the formation of uric acid as its major excretory product of waste nitrogen $(29,42)$.

\section{Labeling of urinary purines in patients with pri- mary gout}

Three patients with primary gout were studied, one excreting normal quantities of uric acid in urine, one excreting amounts somewhat in excess of normal, and one excreting decidedly abnormal amounts. In Figure 4 are shown results obtained in gouty subject D. W., who excreted $317 \mathrm{mg}$. of uric acid daily. The most striking finding of this study was the level of 7-methylguanine enrichment on the first day, which was twice that of uric acid of that day, and one-third higher than the peak uric acid value found on the second day. The enrichment of adenine in the first day sample was also greater than that of uric acid. In contrast to the control studies, the first day hypoxanthine enrichment was of small magnitude in comparison with that of uric acid in this subject, whose fractional incorporation of administered glycine-1- $\mathrm{C}^{14}$ into urinary uric acid was about three times normal (8).

In Figure 5 are shown data on E. H., a gouty subject excreting $1,050 \mathrm{mg}$. of uric acid daily. Uric acid was maximally labeled on Day 1 , and the cumulative incorporation of label into urinary uric acid was some four times normal (8). $\mathrm{Hy}-$ poxanthine labeling was also maximal on Day 1 , and its specific activity curve seemed to parallel

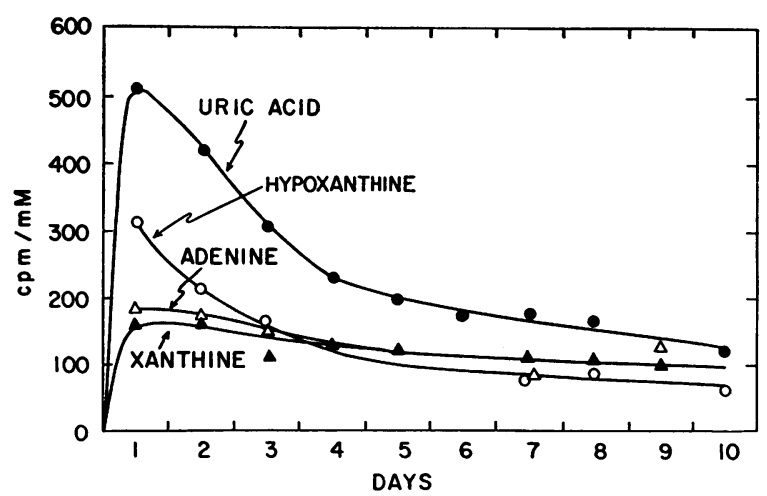

Fig. 5. Specific Activity Values of Urinary Purines of Gouty Subject E. N., Following Oral AdMINISTRATION OF $5 \mu \mathrm{C}$. OF GLYCINE-1-C ${ }^{14}$

This subject excreted an average of $1,054 \mathrm{mg}$. of urio acid daily during this study. 


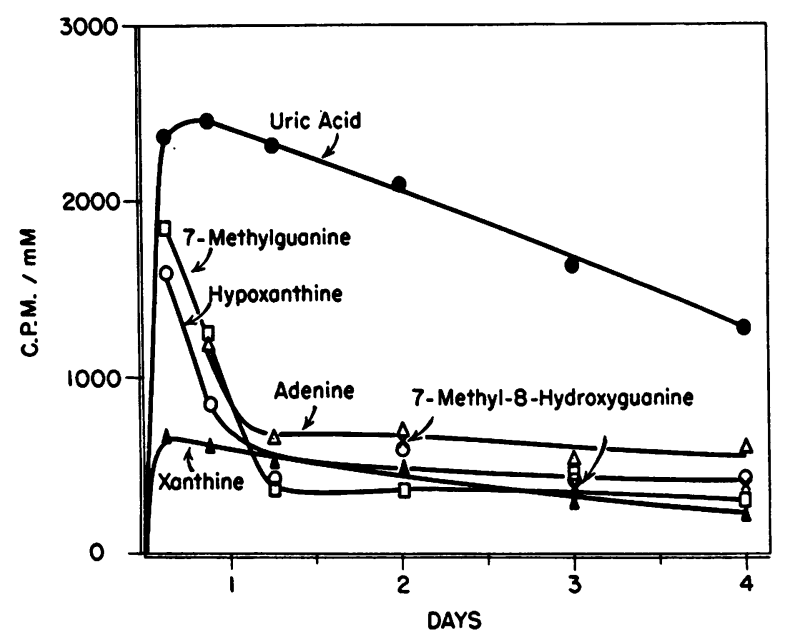

Fig. 6. Specific Activity Values of Urinary Purines in Gouty Subject H. H., Following Oral Administration of $25 \mu \mathrm{c}$. OF Glycine-1-C ${ }^{14}$

that of uric acid. Nevertheless, the hypoxanthine specific activity values were at all times considerably less than those of uric acid. It was, however, appreciated that an extremely rapid turnover of the hypoxanthine pool in both gouty subjects D. W. and E. H. might have yielded highly labeled uric acid, as observed, and that the maximal labeling of urinary hypoxanthine might not be discernible within a 24 hour sample. For this reason, a third gouty subject was studied in whom fractional urine samples were obtained during the first day.

Figure 6 shows data obtained on H. H., a gouty subject excreting an average of $685 \mathrm{mg}$. of uric acid per day. Uric acid enrichment was maximal between 6 and 12 hours following oral administration of $25 \mu \mathrm{c}$. of glycine-1- $\mathrm{C}^{14}$, and the cumulative incorporation of $\mathrm{C}^{\mathbf{1 4}}$ into urinary uric acid was 0.19 per cent in four days, a value about 2.5 times normal (8). The labeling of other purines was greatest in 7-methylguanine, hypoxanthine, and adenine. However, the shapes of the curves suggest that specific activity values were probably higher during the initial hours than is reflected in the pooled 0 to 6 hour sample. It is to be noted that in this patient, as in patient D. W., the early specific activity values of 7 -methylguanine are high compared with results in the two control subjects. In this subject, studied during the waning days of a prolonged attack of acute gouty arthritis, the urinary excretion of 7-methyl-8-hydroxyguanine was about $5 \mathrm{mg}$. per day, a value two to three times normal (20). Three samples of this purine were successfully isolated, and specific activity values were similar to those of other purines on Days 2 to 4 .

These studies suggest that the prompt excessive synthesis of uric acid found in gouty subjects may involve early cleavage of purine nucleotides, as in normal subjects. The high early labeling of 7-methylguanine in two gouty subjects, not found in the control subjects, is of interest. The observation that urinary excretion of 7 -methyl8-hydroxyguanine may be increased during acute gouty attacks $(11,43)$, demonstrated again in patient $H$. H., further directs attention toward guanine compounds in this disease.

In order to determine to what extent the 7-methylguanine enrichment pattern might be specific for patients with primary gout, it was decided to conduct similar studies on patients with known overproduction of uric acid involving excessive turnover of nucleoproteins.

\section{Labeling of urinary uric acid in patients with pro- liferative hematopoietic disorders}

Since the quantities of uric acid excreted by patient D. D., a female with myeloid metaplasia, and by patient J. H., a male with polycythemia and secondary gout, were considerably greater than those of control subjects, the $\mathrm{C}^{14}$ enrichment data

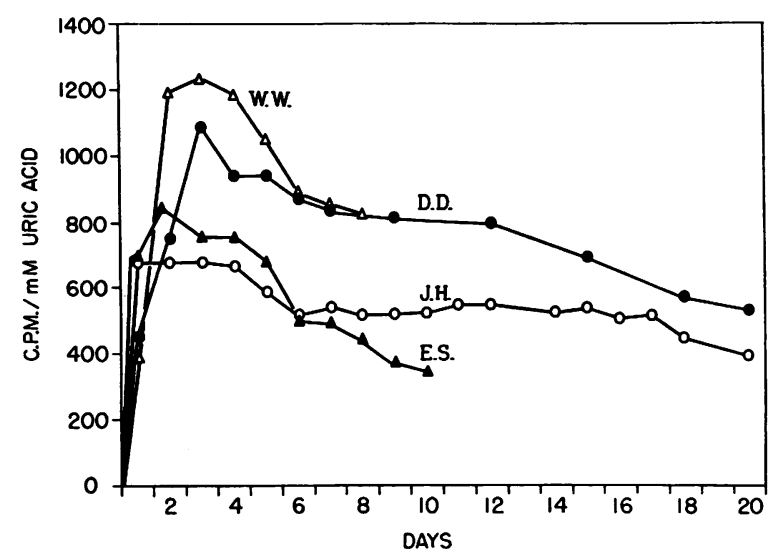

Fig. 7. Specific Activity Values of Urinary Uric Acid in Male Control W. W., and a Male Subject with Polycythemia Vera and Secondary Gout, J. H., and in Female Control Subject E. S., and a Female Subject with Myeloid Metaplasia and HyperuriCEMIA, D. D.

Values have been adjusted to a standard dose of $20 \mu \mathrm{c}$. of glycine-1-C $\mathrm{C}^{\mathbf{4}}$ 


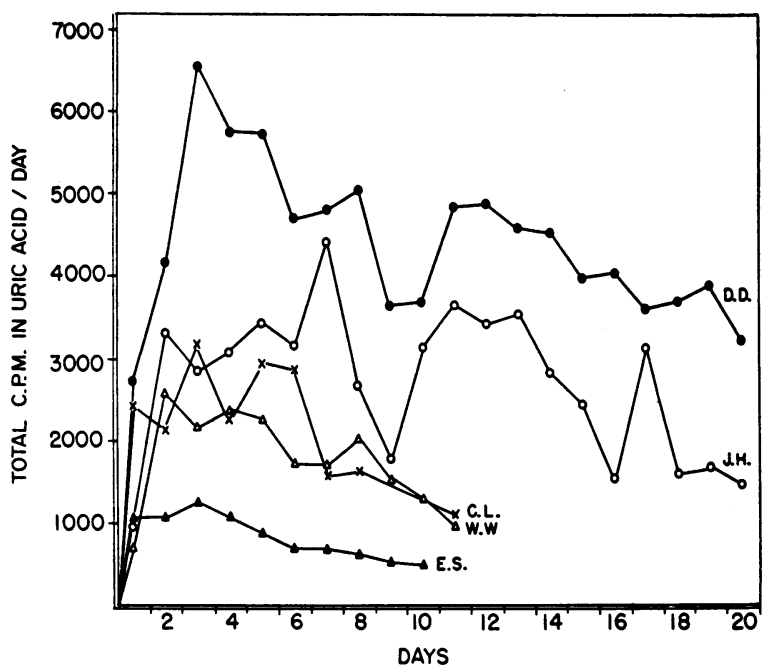

Fig. 8. Total $C^{16}$ in Daily Uric Acid Samples

Subjects as described in legend of Figure 7. In addition, data on a second male control subject, C. L., have been included. Note the secondary phases of uric acid enrichment in subjects D. D. and J. H.

are plotted in terms of concentration (Figure 7) and total quantity of $\mathrm{C}^{14}$ (Figure 8 ) in daily samples of urinary uric acid, ${ }^{7}$ and in terms of cumulative excretion of $\mathrm{C}^{14}$ in uric acid (Figure 9). Although in both patients there is marked early enrichment of uric acid, in neither is the initial (first day) synthesis of uric acid-C ${ }^{14}$ clearly greater than in control subjects, as is regularly found in patients with primary gout (8). In both patients D. D. and J. H. there is, however, evidence for a secondary phase of incorporation of $\mathrm{C}^{14}$ into uric acid, maximal on about the eleventh to thirteenth days (Figure 8). This second phase of enrichment is in good agreement with the time of occurrence of isotope maxima in uric acid following glycine- $\mathrm{N}^{15}$ administration (9, 10, 12). The purine intermediates involved in these two

7 Wide fluctuations in uric acid excretion occurred in patients D. D. and J. H. Low outputs on Days 9 and 10 in D. D. and Day 9 in J. H., as well as high outputs on Days 7 and 17 in J. H., have perhaps introduced fortuitous effects in Figure 8. The difference in $\mathrm{C}^{16}$ uric acid output between control and experimental subjects is most remarkable on Days 10 and 11. Although the data on control subjects have not been extended beyond 11 days in the present study, other studies have shown that there is no secondary late accentuation of uric acid labeling in control or primary gouty subjects (12) such as has been demonstrated here and elsewhere (12) in patients with myeloproliferative disorders. phases of uric acid production were studied in patient D. D.

\section{Labeling of urinary purine bases in a patient with myeloid metaplasia}

In Figure 10 are plotted the specific activity values of adenine, guanine, 7-methylguanine, hypoxanthine, xanthine and uric acid over a 15 day period following administration of $20 \mu \mathrm{c}$. of glycine-1-C $\mathrm{C}^{14}$ to subject $\mathrm{D}$. D. The specific activities of all purine bases exceeded that of uric acid on Day 1 , xanthine by about 15 per cent, hypoxanthine by twofold, guanine and 7-methylguanine by more than threefold, and adenine by more than sixfold. There is an immediate sharp decline in specific activity of these bases such that xanthine and 7-methylguanine reach low values by the second day. Minimal values of adenine and hypoxanthine are not reached for five to seven days, and these results are presumably a reflection of the slow rate of turnover of the adenine pool (44). Uric acid reached maximal enrichment on Day 3 and thereafter declined in $\mathrm{C}^{\mathbf{1 4}}$ concentration. The secondary phase of uric acid enrichment demonstrated above is now seen to be a reflection of secondary maxima occurring also in the various purine bases. The parallelism of the enrichment curve of 7-methylguanine (and guanine) with that of xanthine, and of adenine with that of hypoxanthine, are worthy of note, as is the lack of a close correlation between the shapes of the hypoxanthine and xanthine curves themselves. These relationships have certain implications regarding precursor-product relationships. Suffice it to say here that Figure 10 is believed to present

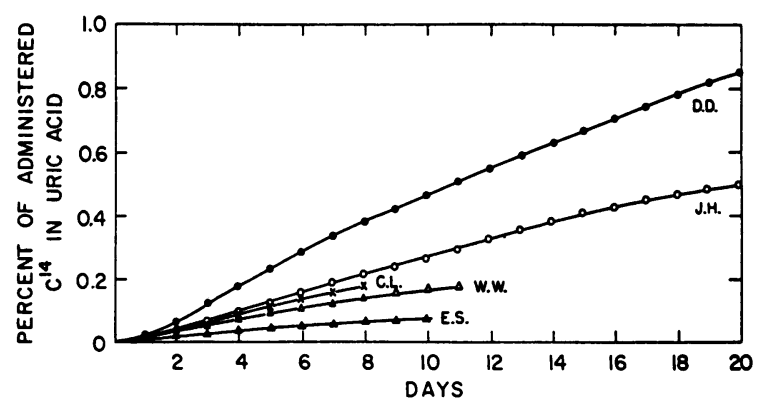

Fig. 9. Cumulative Incorporation of Cis Into UriNary Uric Acid of Subjects Described in Legends of Figures 7 AND 8

Data are plotted in per cent of administered dose versus time. 
evidence for two classes of pathways of uric acid synthesis, differing remarkably in rate, but involving the same intermediates. The rapid process, yielding significant labeling of purine bases on Day 1 , is reflected in a rapid enrichment of uric acid. The slower process, yielding secondary maxima in purine bases 7 to 11 days later, is in turn reflected in a second week enrichment peak in uric acid. This late process is quite consistent with known time relationships of ribonucleic acid turnover $(45,46)$, although other mechanisms, such as reutilization of glycine moieties released from protein, might also be entertained.

\section{DISCUSSION}

From the knowledge that purine bases are not formed de novo, but are rather generated as ribotides $(35,36,38,39,47-49)$, it follows that the prompt appearance of highly labeled purine bases in urine results from cleavage of newly formed nucleotides. There is evidence for the existence of this mechanism in all subjects of the present study, although there is no way of determining from the data of this paper whether ribotides or deoxyribotides are primarily involved. Insofar as the bases generated are hypoxanthine, xanthine, or guanine, mechanisms exist for their prompt oxidation to uric acid. Hypoxanthine is readily oxidized to uric acid via xanthine by xanthine oxidase $(14,27)$. Guanine is deaminated by guanase to form xanthine (13), which is then converted to uric acid by xanthine oxidase. Adenine, however, cannot be directly deaminated in man $(50)$ so that free adenine is converted to uric acid only following reincorporation as riboside (40) or ribotide (51) and further metabolism via inosine or inosinic acid (39).

Since it is known that nucleoside phosphorylase attacks inosine and guanosine much more readily than adenosine $(40,41,52)$ or xanthosine $(53)$, it might be anticipated that stepwise cleavages of inosinic acid to hypoxanthine and of guanylic acid to guanine, with subsequent conversion of the free bases to uric acid, would constitute major pathways of the shunt mechanism. The isotope data in the control subjects accord with these anticipations. In both subjects the initial high labeling of hypoxanthine provides strong indication that cleavage of inosinic acid constitutes a major pathway for direct synthesis of uric acid. The early

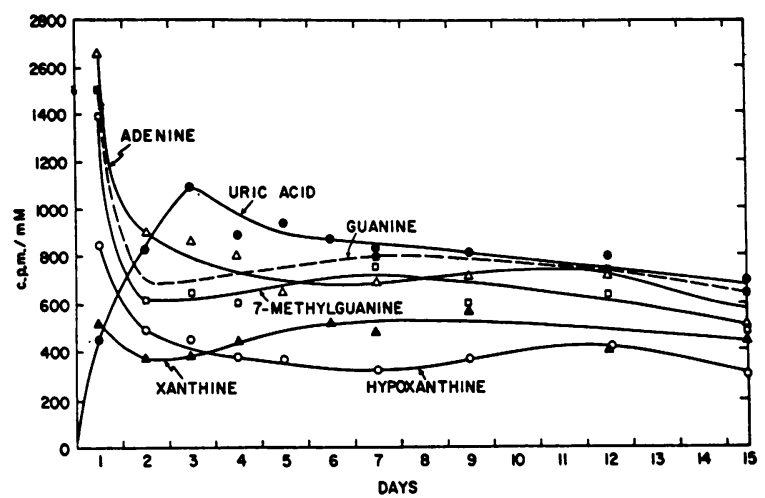

Fig. 10. Specific Activity Values of Urinary Purines in D. D., a Patient with Myeloid Metaplasia Who Received $20 \mu \mathrm{c}$. OF Glycine-1-C ${ }^{14}$ Orally

Note particularly the high initial specific activity values of all purine bases and the secondary maxima occurring on Days 7 to 12 , illustrating two distinct mechanisms for synthesis of labeled uric acid.

Permission was granted by Grune \& Stratton, Inc. to reproduce this figure which originally appeared in $\mathrm{ME}$ TABOLISM, volume 6, pp. 244-268, 1957.

labeling of guanine in subject C. L. and of 7-methylguanine $^{B}$ in subject $H$. B. suggest that the guanylic acid cleavage pathway accounts for a smaller portion of the early labeling of uric acid.

In the patient with myeloid metaplasia, the very high specific activity values of guanine compounds, and of adenine, suggest that direct pathways involving nucleotides of guanine and adenine were quantitatively of greater than usual significance. In view of the recognized overproduction of nucleic acids in this subject, the high labeling of bases derived from these nucleotides is not surprising. Weissmann, Bromberg, and Gutman (28) have observed initial high $\mathrm{N}^{15}$ labeling of 7-methylguanine, 7-methyl-8-hydroxyguanine and adenine in a patient with polycythemia vera given glycine- $\mathrm{N}^{15}$, so that the isotope relationships observed in subject D. D. may be common in patients with proliferative hematopoietic disorders.

The major goal of this study was the acquisition of information regarding mechanisms by which persons with primary gout synthesize uric acid excessively. Time relationships suggest that overproduction of uric acid by these subjects occurs without the intermediary intervention of nucleic acids $(5,7,8)$. The data presented suggest further that rapid synthesis of labeled urate in these patients occurs via nucleotide cleavage pathways, as in normal subjects and patients with myelo- 
proliferative disorders, but to a quantitatively excessive extent, and possibly at an accelerated rate, in that even short initial collection periods failed to reveal the true maximal initial enrichment. Furthermore, in both the gouty patients and the subjects with myeloid metaplasia, the labeling of guanine compounds appeared to be greater and to occur earlier than in normals. Since in patients with myeloproliferative disorders a generalized overproduction of nucleotides is of necessity present as an accompaniment of the accelerated turnover of nucleic acids, the similarity of the initial labeling patterns of urinary purines in the patient with myeloid metaplasia and in subjects with primary gout suggests that the patterns observed in primary gout may also be a reflection of overproduction of various nucleotides from glycine and other small molecules. Again, the possibility that deoxyribotides may participate must be kept in mind. At any rate, it appears unlikely that the metabolic error of primary gout consists solely of an accentuation of a single cleavage pathway. The data of the present paper implicate overproduction of uric acid probably via inosinic acid, and abnormal labeling of 7-methylguanine. Recent data from Gutman's laboratory $(12,43)$ implicate altered excretions of 6-succinoaminopurine (the aglycone of the intermediate ribotide in the inosinic-adenylic acid transformation), and 7-methyl-8-hydroxyguanine (of unknown origin) during the acute gouty attack. Thus, the gouty derangement would appear to be complex, indeed, and probably to involve several compounds at the nucleotide level. It is not possible at present to formulate a hypothesis based on a single missing or deficient enzyme that would adequately explain these findings. It may be, however, that the metabolic defect of primary gout involves primarily a defect in regulation of rates of nucleotide synthesis rather than a specific missing reaction. The findings of Seegmiller, Laster, and Stetten (54) that aminoimidazole carboxamide given concomitantly with glycine- $\mathrm{N}^{15}$ reduces the incorporation of $\mathrm{N}^{15}$ into urinary uric acid in both normal and gouty persons, but frequently less so in the gouty, indicates that purine nucleotide synthesis in man is subject to regulatory mechanisms which may be defective in primary gout.

Possible reasons for the differences obtained with glycine- $\mathrm{N}^{15}$ and glycine-1-C $\mathrm{C}^{14}$ in studies of uric acid generation in primary gout have previously been discussed (8). It was demonstrated that the quantity of glycine administered as glycine- $\mathrm{N}^{15}$ was in excess of tracer levels, and that the magnitude of early incorporation of label into uric acid was percentually low as a consequence. The results obtained in patients with proliferative hematopoietic disorders (D. D. and J. H.) with glycine-1- $\mathrm{C}^{14}$ are also different from those reported with glycine- $\mathrm{N}^{15}$. With the $\mathrm{N}^{15}$ technique the early phase of isotope incorporation is not as much in evidence, a rather smooth increase in isotope concentration of uric acid usually being seen, reaching a maximum at about 10 to 15 days (9, $10,12)$. The studies with tracer doses of glycine-1- $\mathrm{C}^{14}$ have, however, shown clearly that there are two major phases to this incorporation process. Although the results of both processes have been interpreted in terms of known reactions, accessory pathways of nucleotide and purine synthesis leading to production of uric acid have not been excluded. The time lapses between peak enrichments of primary precursor purines and uric acid in some studies, e.g., control subject C. L. (Figure 2) and patient D. D. (Figure 10), raise such possibilities. Potential reactions of this type, e.g., involving an intermediary role of uric acid riboside, have been discussed (4). It would seem more likely, however, that these isotope relationships, as well as the lack of conventional precursor product concentration relationships of hypoxanthine, xanthine, and uric acid, or of guanine and xanthine, are manifestations of the complexities of kinetics of body pools of intermediates, and of the limitations of information obtainable from urinary products having diverse origins. Thus these studies, although suggestive of types of mechanisms involved in uric acid synthesis, will have to be supplemented by more detailed studies of reactions conducted in isolated tissue systems. Such studies are now in progress.

\section{SUMMARY}

1. Procedures are described for isolation from urine of hypoxanthine, xanthine, adenine, guanine, 7-methylguanine and 7-methyl-8-hydroxyguanine in crystalline form suitable for measurement of $\mathrm{C}^{14}$ content.

2. These purine bases have been isolated following administration of glycine-1-C $\mathrm{C}^{14}$ to control 
subjects and patients with primary gout or myeloid metaplasia. Specific activity values have been compared with those of uric acid over variable periods of time in normal subjects and in patients with disorders of purine metabolism.

3. Two major mechanisms exist by which uric acid is generated in man. In addition to the traditional reactions by which catabolism of nucleic acids gives rise to purine bases susceptible of subsequent conversion to uric acid, there appear to be nucleotide cleavage reactions which yield highly labeled purine bases in urine within hours after administration of glycine-1-C ${ }^{14}$.

4. It is proposed that in normal and gouty subjects the synthesis of labeled uric acid from glycine-1-C ${ }^{14}$ occurs primarily via the "shunt" mechanism; in contrast, in the patient with myeloid metaplasia, a second mechanism, presumably that of augmented nucleic acid turnover, accounted for the late (second week) synthesis of considerable additional labeled uric acid.

5. On the basis of the patterns of labeling of urinary purines in patients with primary gout, and a comparison of these patterns with the initial purine labeling pattern of a patient with myeloid metaplasia and generalized overproduction of nucleotides, it is proposed that patients with primary gout may also have faulty regulation of rates of nucleotide synthesis, and that in these patients, in contrast to those with myeloproliferative disorders, excessive purine nucleotide synthesis is followed by rapid conversion of surplus purine bases to uric acid. The data suggest that several purine nucleotides may be involved in the derangement of purine metabolism of primary gout.

\section{REFERENCES}

1. Wyngaarden, J. B. Pathways of urate synthesis in gout (abstract). J. clin. Invest. 1955, 34, 973.

2. Wyngaarden, J. B., and Blair, A. Pathways of urate synthesis in gout. Ann. rheum. Dis. 1955, 14, 433.

3. Wyngaarden, J. B., Blair, A., and Schuck, J. On the mechanism of the "shunt" pathway of uric acid synthesis. Clin. Res. Proc. 1957, 5, 108.

4. Wyngaarden, J. B. Intermediary purine metabolism and the metabolic defects of gout. Metabolism 1957, 6, 244.

5. Benedict, J. D., Roche, M., Yü, T. F., Bien, E. J., Gutman, A. B., and Stetten, D., Jr. Incorporation of glycine nitrogen into uric acid in normal and gouty man. Metabolism 1952, 1, 3.

6. Benedict, J. D., Yü, T. F., Bien, E. J., Gutman, A. B., and Stetten, D., Jr. A further study of the utili- zation of dietary glycine nitrogen for uric acid synthesis in gout. J. clin. Invest. 1953, 32, 775.

7. Stetten, D., Jr. Recent contributions to the understanding of the metabolic defect in gout. Geriatrics 1954, 9, 163.

8. Wyngaarden, J. B. Overproduction of uric acid as the cause of hyperuricemia in primary gout. $\mathrm{J}$. clin. Invest. 1957, 36, 1508.

9. Yü, T. F., Wassermann, L. R., Benedict, J. D., Bien, E. J., Gutman, A. B., and Stetten, D., Jr. A simultaneous study of glycine- $\mathrm{N}^{15}$ incorporation into uric acid and heme, and of $\mathrm{Fe}^{50}$ utilization, in a case of gout associated with polycythemia secondary to congential heart disease. Amer. J. Med. $1953,15,845$.

10. Laster, L., and Muller, A. F. Uric acid production in a case of myeloid metaplasia associated with gouty arthritis, studied with $\mathrm{N}^{15}$-labeled glycine. Amer. J. Med. 1953, 15, 857.

11. Gutman, A. B., Yü, T. F., and Weissmann, B. The concept of secondary gout; relation to purine metabolism in polycythemia and myeloid metaplasia. Trans. Ass. Amer. Phycns 1956, 69, 229.

12. Yü, T. F., Weissmann, B., Sharney, L., Kupfer, S., and Gutman, A. B. On the biosynthesis of uric acid from glycine- $\mathrm{N}^{15}$ in primary and secondary polycythemia. Amer. J. Med. 1956, 21, 901.

13. Kalckar, H. M. Differential spectrophotometry of purine compounds by means of specific enzymes. III. Studies of the enzymes of purine metabolism. J. biol. Chem. 1947, 167, 461.

14. Kalckar, H. M. Differential spectrophotometry of purine compounds by means of specific enzymes. I. Determination of hydroxypurine compounds. J. biol. Chem. 1947, 167, 429.

15. Praetorius, E. An enzymatic method for the determination of uric acid by ultraviolet spectrophotometry. Scand. J. clin. Lab. Invest. 1949, 1, 222.

16. Hunter, A., and Givens, M. H. The metabolism of endogenous and exogenous purines in the monkey. J. biol. Chem. 1914, 17, 37.

17. Krüger, M., and Schmid, J. Zur Bestimmung der Harnsäure und Purinbasen im menschlichen Harn. Hoppe-Seylers Z. physiol. Chem. 1905, 45, 1.

18. Folin, O. Laboratory Manual of Biological Chemistry, 5th ed. New York, D. Appleton and Co., 1934, p. 299.

19. Neubauer, C. Ueber des quantitative Bestimmung des Sarkins und Xanthins im muskelfleisch. Z. anal. Chem. 1867, 6, 33.

20. Weissmann, B., Bromberg, P. A., and Gutman, A. B. The purine bases of human urine. I. Separation and identification. J. biol. Chem. 1957, 224, 407.

21. Abrams, R., and Bentley, M. Biosynthesis of nucleic acid purines. I. Formation of guanine from adenine compounds in bone marrow extracts. Arch. Biochem. 1955, 56, 184.

22. Wall, J. S. Simultaneous separation of purines, pyrimidines, amino acids, and other nitrogenous 
compounds by ion exchange chromatography. Analyt. Chem. 1953, 25, 950.

23. Weissmann, B., Bromberg, P. A., and Gutman, A. B. Chromatographic investigation of purines in normal human urine. Proc. Soc. exp. Biol. (N. Y.) 1954, 87, 257.

24. Klenow, $H$. The enzymic oxidation and assay of adenine. Biochem. J. 1952, 50, 404.

25. Hitchings, G. H., and Falco, E. A. The identification of guanine in extracts of Girella nigricans. The specificity of guanase. Proc. nat. Acad. Sci. (Wash.) 1944, 30, 294.

26. Wyngaarden, J. B. 2,6-Diaminopurine as substrate and inhibitor of xanthine oxidase. J. biol. Chem. 1957, 224, 453.

27. Bergmann, F., and Dikstein, S. Studies on uric acid and related compounds. III. Observations on the specificity of mammalian xanthine oxidase. J. biol. Chem. 1956, 223, 765.

28. Weissmann, B., Bromberg, P. A., and Gutman, A. B. The purine bases of human urine. II. Semiquantitative estimation and isotope incorporation. $\mathrm{J}$. biol. Chem. 1957, 224, 423.

29. Schulman, M. P., Sonne, J. C., and Buchanan, J. M. Biosynthesis of the purines. I. Hypoxanthine formation in pigeon liver homogenates and extracts. J. biol. Chem. 1952, 196, 499.

30. Levene, P. A. Preparation and analysis of animal nucleic acid. J. biol. Chem. 1922, 53, 441.

31. Levene, P. A. Darstellung und Analyse einiger Nucleinsäuren. Hoppe-Seylers Z. physiol. Chem. 1903, 39, 4.

32. Robinson, C. V. Windowless, flow-type proportional counter for counting $C^{14}$. Science 1950, 112, 198.

33. Kamen, M. D. Radioactive Tracers in Biology, an Introduction to Tracer Methodology. New York, Academic Press Inc., 1947, p. 87.

34. Hurlbert, R. B., Schmitz, H., Brumm, A. F., and Potter, V. R. Nucleotide metabolism. II. Chromatographic separation of acid-soluble nucleotides. J. biol. Chem. 1954, 209, 23.

35. Goldthwait, D. A., Peabody, R. A., and Greenberg, G. R. On the occurrence of glycinamide ribotide and its formyl derivative. J. biol. Chem. 1956, 221, 555.

36. Levenberg, B., and Melnick, I. Formylglycinamidine ribotide and 5-aminoimidazole ribotide-intermediates in purine biosynthesis. Fed. Proc. 1956, 15, 117.

37. Lukens, L. N., and Buchanan, J. M. 5-Amino-4carboxy-imidazole ribotide, a new intermediate in purine biosynthesis. Fed. Proc. 1957, 16, 214.

38. Buchanan, J. M., and Schulman, M. P. Biosynthesis of the purines. III. Reactions of formate and inosinic acid and an effect of the citrovorum factor. J. biol. Chem. 1953, 202, 241.

39. Greenberg, G. R. De novo synthesis of hypoxanthine via inosine-5-phosphate and inosine. J. biol. Chem. 1951, 190, 611.
40. Kalckar, H. M. The enzymatic synthesis of purine ribosides. J. biol. Chem. 1947, 167, 477.

41. Korn, E. D., and Buchanan, J. M. Biosynthesis of the purines. VI. Purification of liver nucleoside phosphorylase and demonstration of nucleoside synthesis from 4-amino-5-imidazolecarboxamide, adenine, and 2,6-diaminopurine. J. biol. Chem. 1955, 217, 183.

42. Baldwin, E. Dynamic Aspects of Biochemistry, 2nd ed. Cambridge, Cambridge University Press, 1952, p. 324.

43. Gutman, A. B., and Yü, T. F. Renal function in gout. With a commentary on the renal regulation of urate excretion, and the role of the kidney in the pathogenesis of gout. Amer. J. Med. 1957, 23, 600.

44. Wyngaarden, J. B., Seegmiller, J. E., Blair, A. E. and Schuck, J. On the mechanisms of utilization of hypoxanthine, adenine and 5-amino-4-imidazolecarboxamide for uric acid synthesis in man. To be published.

45. Furst, S. S., Roll, P. M., and Brown, G. B. On the renewal of the purines of the desoxypentose and pentose nucleic acids. J. biol. Chem. 1950, 183, 251.

46. Bendich, A. Studies on the metabolism of the nucleic acids. Exp. Cell Res. 1952, Suppl. 2, 181.

47. Lieberman, I. Enzymatic synthesis of adenosine-5' phosphate from inosine-5'-phosphate. J. biol Chem. 1956, 223, 327.

48. Abrams, R., and Bentley, M. Transformation of inosinic acid to adenylic and guanylic acids in a soluble enzyme system. J. Amer. chem. Soc. 1955, 77, 4179.

49. Lagerkvist, U. Enzymic synthesis of xanthosineand guanosine-5-phosphate from inosine-5-phosphate. Acta chem. scand. 1955, 9, 1028.

50. Schmidt, G. Nucleases and enzymes attacking nucleic acid components in The Nucleic Acids, E. Chargaff, and J. N. Davidson, Eds. New York, Academic Press Inc., 1955, vol. I, p. 555.

51. Korn, E. D., Remy, C. N., Wasilejko, H. C., and Buchanan, J. M. Biosynthesis of the purines. VII. Synthesis of nucleotides from bases partially purified enzymes. J. biol. Chem. 1955, 217, 875.

52. Huennekens, F. M., Nurk, E., and Gabrio, B. W. Erythrocyte metabolism. I. Purine nucleoside phosphorylase. J. biol. Chem. 1956, 221, 971.

53. Friedkin, M. Enzymatic synthesis of desoxyxanthosine by the action of xanthosine phosphorylase in mammalian tissue. J. Amer. chem. Soc. 1952, 74, 112.

54. Seegmiller, J. E., Laster, L., and Stetten, D., Jr. Uric acid formation in patients with gout. The incorporation of 4-amino-5-imidazolecarboxamide$\mathrm{C}^{13}$ into uric acid. Ninth Internat. Congress on Rheumatic Diseases, 1957, Programme Vol. 2, 207. 